\title{
|EL INÉDITO ESCENARIO CONSTITUCIONAL PERUANO: CRISIS POLÍTICA Y SALIDA CONSTITUCIONAL
}

Elena Alvites ${ }^{1}$

El artículo $134^{2}$ de la Constitución peruana dispone que el Presidente de la República tiene la facultad de disolver el Congreso de la República si este órgano ha censurado o rehusado dar la confianza a dos Consejos de Ministros. Esta facultad constitucional forma parte de régimen político constitucional peruano que, siendo presidencialista, incorpora instituciones propias del régimen parlamentario, como la censura, el pedido de cuestión de confianza y el voto de investidura de parte del Congreso de la República a un gabinete de ministros, cuyo presidente y ministros integrantes, son nombrados-y también removidos-por el Presidente de la Republica que, al igual que el Congreso, es elegido por votación popular. A través de dichas instituciones, las Constitución peruana busca salvaguardar el equilibrio de poderes en el escenario de las relaciones entre el Poder Ejecutivo y el Poder Legislativo, en el ejercicio de sus funciones constitucionales; vale decir, son instrumentos constitucionales orientados a que buscan institucionalizar las tensiones políticas entre el Poder Ejecutivo, encabezado por el Presidente de la República, y las mayorías parlamentarias.

Precisamente, en el ese marco normativo, y particularmente en aplicación del mencionado artículo 134, el pasado 30 de setiembre, el Presidente peruano, Martín Vizcarra, disolvió el Congreso de la República, debido a que este rehusó darle la confianza, esta vez de forma implícita, al segundo gabinete ministerial que hizo cuestión de confianza en el periodo de gobierno 2016-2021. En esa oportunidad, como veremos, el pedido de confianza se vinculó a un proyecto de ley proveniente del Poder Ejecutivo que buscaba mejorar el proceso de elección de los magistrados del Tribunal Constitucional, dotándolo de garantías de transparencia para posibilitar el escrutinio público en un contexto en el que la población desconfía de la mayoría de la clase política del país, debido a que altos funcionarios del Estado, como congresista, jueces y hasta los cuatro último ex presidentes de la República, vienen siento investigados por delitos de corrupción.

Sin embargo, el ejercicio de la Facultad presidencial de disolver el Congreso no se trató de una medida aislada, sino que constituye el cierre de un proceso de constante enfrentamiento y tensión política que desde el año 2016 se viene dando entre el Pode Ejecutivo y el Congreso de la República; proceso, en el que la mayoría parlamentaria del partido fujimorista y sus aliados, en más

\footnotetext{
1 Doctora en Derecho por la Universidad de Alicante; Profesora ordinaria principal del Departamento de Derecho de la Pontificia Universidad Católica del Perú; Campus principal, Avenida Universitaria, 1801, San Miguel Lima 32, Perú; https://orcid.org/0000-0001-5220-8899; ealvites@pucp.edu.pe

2 Constitución Política del Perú. Artículo 134. Disolución del Congreso. El Presidente de la República está facultado para disolver el Congreso si éste ha censurado o negado su confianza a dos Consejos de Ministros. El decreto de disolución contiene la convocatoria a elecciones para un nuevo Congreso. Dichas elecciones se realizan dentro de los cuatro meses de la fecha de disolución, sin que pueda alterarse el sistema electoral preexistente. No puede disolverse el Congreso en el último año de su mandato. Disuelto el Congreso, se mantiene en funciones la Comisión Permanente, la cual no puede ser disuelta. No hay otras formas de revocatoria del mandato parlamentario. Bajo estado de sitio, el Congreso no puede ser disuelto.
} 
de una ocasión, han actuado rompiendo el equilibrio de poderes que debe existir en todo Estado Constitucional. En esa línea, también puede decirse que fue la respuesta política-pero dentro de los cauces constitucionales-que adoptó el jefe del Poder Ejecutivo para poner fin al mencionado enfrentamiento, frente a la negativa del Congreso de adoptar a una fórmula consensuada para solucionarlo. Ello, debido a que previamente el Congreso desestimó la propuesta de adelanto de elecciones generales realizada en julio de este año por el propio Presidente, ${ }^{3}$ sin mayor debate en la representación nacional.

En efecto, resulta imposible entender la disolución del Parlamento, si se obvian los antecedentes de la tensa relación que, desde el inicio del periodo de gobierno en el año 2016, se entabló entre el Poder Legislativo y el Poder Ejecutivo. Incluso, es necesario indicar que, en ocasiones, tal tensión escaló al nivel de real enfrentamiento, dado que la mayoría parlamentaria en más de una ocasión actuó fuera de le exigencia del ejercicio equilibrado de las funciones congresales. Eso sucedió, por ejemplo, con: los dos pedidos-y una votación—de vacancia del presidente de la República por la cuestionada causal de incapacidad moral (2017 y 2018); la renuncia de un Ministro de Educación ante su eventual censura relacionada con la política educativa inclusiva y con perspectiva de género (2016); la censura de un Ministro de Economía y Finanzas (2017); la primera negación de confianza por parte del Congreso, generando la crisis total del gabinete ministerial en relación con la política pública implementada por el Ministerio de Educación (2017); y, la convocatoria a legislatura extraordinaria por parte del Presidente de la República para obligar al Congreso a debatir y adoptar un acuerdo sobre la remoción de todos los integrantes del Consejo Nacional de la Magistratura (CNM) que venían siendo investigado por la comisión de delitos de corrupción (2018). También es importante mencionar, los dos pedidos de confianza que tuvieron que realizar dos Presidentes del Consejo de Ministros para que el Congreso revise, debata y vote proyectos de ley-incluyendo proyectos de reforma constitucional-destinados a fortalecer la institucionalidad democrática y la lucha contra la corrupción (2018). Asimismo, hubo por parte de la mayoría parlamentaria abierta protección a altos funcionarios del Estado investigados por delitos de corrupción, como el caso del ex juez supremo César Hinostroza Pariachi-prófugo y en proceso de extradición autorizado por la Audiencia Nacional de España - y el ex Fiscal de la Nación Pedro Gonzalo Chávarry Vallejos.

En ese contexto, el congreso de la República, en el mes de setiembre, buscó elegir, de manera célere pero a la vez opaca y sin mayor escrutinio público a seis de los siete integrantes del Tribunal Constitucional. Este procedimiento, ciertamente, tenía cobertura legal, dado que la convocatoria por invitación se encuentra prevista en la Ley Orgánica del Tribunal Constitucional; sin embargo, la forma en que fue llevado a cabo no garantizaba transparencia en la elección de los magistrados

Proyecto de Ley 4637/2019-PE, "Proyecto de Ley de reforma constitucional que prohíbe la postulación de quien ejerce la presidencia de la República y adelanta las elecciones generales", cuyo objetivo es incorporar en la Constitución, a través del proceso de reforma constitucional, disposiciones transitorias especiales para recortar los mandatos del presidente de la República, los congresistas y los representantes del Perú ante el Parlamento Andino, y convocar a elecciones generales en el año 2020. 
constitucionales que posteriormente, sin las suficientes garantías de independencia e imparcialidad, serían los encargados de ejercer el control constitucional y la protección en última instancia de los derechos fundamentales.

Precisamente, la forma en que se estaba llevando a cabo dicho proceso de elección de magistrados, motivó al Poder Ejecutivo a realizar una propuesta legislativa de reforma de la Ley Orgánica del Tribunal Constitucional, para mejorar el proceso de elección en curso, a través de la incorporación de garantías de transparencia y participación de la población. La revisión y debate de esta propuesta fue vinculada a una solicitud o pedido de confianza por parte del Presidente del Consejo de Ministros, Salvador Del Solar, como una propuesta legislativa que formaba parte de su política de fortalecimiento institucional y prevención de la corrupción. El objetivo del Poder Ejecutivo no era impedir que el Congreso cumpla con su función de elección de los integrantes del Tribunal Constitucional, sino aportar a salvaguardar las garantías de independencia e imparcialidad del órgano de control de la Constitución.

Como el pedido de confianza estaba directamente vinculado con al opaco proceso de elección de magistrados iniciado por el Congreso de la República, el Presidente del Consejo de Ministros al plantear la confianza, señaló que de continuarse con dicho proceso tal pedido de confianza se entendería como denegado. Sin embargo, en desmedro de la confianza solicitada durante la mañana del 30 de setiembre, el Pleno del Congreso de la República dio inicio el proceso de votación y elección de nuevos miembros para el Tribunal Constitucional, llegándose a votar, incluso, por dos de los aspirantes invitados. Estos hechos_además de la votación realizada previamente para diferir la atención del pedido de confianza-, evidencian de manera inequívoca la voluntad del Congreso de rehusar el pedido de confianza solicitado por el presidente del Consejo de Ministros.

De esta forma, por segunda vez durante el periodo de gobiernos iniciado en julio de 2016, se configuró la crisis total del Gabinete y el Presidente de la República, en atención a lo dispuesto por el artículo 134 de la Constitución peruana, ejerció su potestad constitucional de disolver el Congreso. Así, luego de designar al nuevo jefe del Gabinete Ministerial, emitió el Decreto Supremo 165-2019PCM que, conforme al mencionado artículo constitucional, disuelve el pleno del Congreso, revoca el mandato de los congresistas que no forman parte de la Comisión permanente-que debe permanecer en funciones hasta la elección del nuevo Congreso-y convoca a elecciones para el domingo 26 de enero de 2020. De esa manera, se plasmó el mandato constitucional de dejar en manos del pueblo la elección de la nueva conformación congresal y, por ende, la solución del conflicto político entre el Poder Ejecutivo y el Poder Legislativo, para restaurar el equilibrio de poderes.

Nunca antes, desde la vigencia de la Constitución peruana de 1993, se había aplicado el artículo 134 de la Constitución; de ahí que, por ejemplo, actualmente existen dudas y vacíos en cuanto a las reglas a aplicar durante el interregno parlamentario respecto al funcionamiento de la Comisión Permanente del Congreso de la República que, de acuerdo a la Constitución, no puede ser disuelta. Paralelamente, ha subsistido el debate público en cuanto a la corrección de la aplicación de 
dicho artículo constitucional; por ello, el Presidente de la Comisión permanente ha planteado ante el Tribunal Constitucional una demanda de conflicto de competencia contra el Poder Ejecutivo, con la finalidad de que delimite el alcance de la cuestión de confianza respecto a la competencia del Congreso de elegir magistrados constitucionales, y que declare nulo el Decreto Supremo 1652019-PCM, por considerar que disuelve de forma arbitraria el Congreso. Esta demanda, además, se acompañó de una solicitud de la aplicación de una medida cautelar de suspensión de los efectos de dicho decreto.

La demanda de competencia también ha generado debate en torno a la pertinencia constitucional de trasladar al órgano jurisdiccional de control de la Constitución la solución de una controversia considerada esencialmente política, y de cuáles son los límites de Tribunal Constitucional. No obstante, en medio del debate, al cierre de este texto, el Tribunal Constitucional ha admitido a trámite la demanda y ha declarado improcedente el pedido de aplicación de la medida cautelar. ${ }^{4}$ De esa forma, su intervención a través del proceso competencial no afectará el calendario electoral ni la realización las elecciones parlamentarias previstas para enero del año 2020. Incluso, puede ser una oportunidad para que el órgano encargado del control de la Constitución, sin entorpecer el ejercicio democrático de elección del nuevo pleno del Congreso, ejerza su función pacificadora, emitiendo una sentencia prospectiva en la que colabore con el nuevo Congreso. Tal función puede realizarse a través de la identificación de principios que, dentro de los márgenes constitucionales, orienten la adopción de reglas que regulen de manera más precisa los alcances, la oportunidad y el procedimiento de evaluación de la cuestión de confianza, y las formas de negación de ésta. En esa línea, también puede hacer lo propio en relación a la disolución del Congreso, cuanto en la regulación de las funciones y límites de actuación de la Comisión Permanente del Congreso en periodos como el actual en el que, debido a la disolución del pleno del Congreso, dicha Comisión representa al Poder Legislativo peruano.

Ciertamente, se trata de una situación constitucional inédita en el Perú, pero no ha supuesto una ruptura democrática; por el contrario, la intervención directa de la población en la elección de la nueva representación congresal nos sitúa en un escenario democrático. Asimismo, recaerá en el nuevo Congreso, el Poder Ejecutivo y también en el Tribunal Constitucional la responsabilidad de que tal situación sea una oportunidad para la profundización del principio constitucional de equilibrio de poder y la búsqueda de respeto a las formas democráticas, en un escenario en el que la población, frente al extendido problema de corrupción de altos funcionarios y connotados políticos, espera respuesta asertivas en la prevención, investigación y sanción de la corrupción.

Recebido em 02 de dezembro de 2019

Aceito em 02 de dezembro de 2019

\footnotetext{
4 El Tribunal Constitucional no ha hecho pública aún su resolución, pero sí ha expresado en un comunicado el sentido de los votos de sus integrantes: https://www.tc.gob.pe/institucional/notas-de-prensa/comunicado-del-pleno-del-tribunal-constitucional-2/
} 